\title{
Modern IT Application of Research in Physical Education
}

\author{
Zhuo Ni \\ Humanities Department \\ Guangxi Technological College of Machinery and Electricity \\ Nanning, Guangxi, 530007 China
}

\begin{abstract}
With the development of information, technology in the teaching process in college sports has been a certain application. By analyzing the significance of IT for the college physical education, we should emphasize the importance of IT in the teaching process of college sports. Analysis of College PE Teaching Methods and Approaches IT applications are fully integrated with PE Teaching and IT to ensure that it can provide better service for college physical education. With the advent of the information age, more and more high-tech means are into the classroom. IT assisted Physical Education has gradually been adopted by many college sports teachers. IT is used in sports education that is of great significance in terms of teaching concept, teaching methods, teaching methods, but many PE teachers are in the process of integration of IT and teaching college sports. There are some problems, even into the errors. In this paper, the integration of information technology and discipline theory are to explore how to apply information technology in teaching college sports, and effective integration strategy IT and Physical Education.
\end{abstract}

\section{Keywords- IT; College Physical Education; Application}

\section{INTRODUCTION}

School of Physical Education must be consistent with the trend of social development, and be combined with trends in educational development. With the continuous development of information technology in all areas of society, there have been some applications, while modern educational technology has been widely spread in the field of education, video technology, and artificial intelligence technology. The computer technology has been generally applications, through application of these technologies, to some extent, and has contributed to the development and optimization of teaching practice teaching theory. PE curriculum as a quality education constitutes a very important aspect, we must advance with the times, with full use of information technology to effectively enhance the quality of teaching, thus improving the overall quality of students. Therefore, in the process of teaching college sports, we must strengthen the application of information technology, so that it can achieve the desired effect of teaching.

\section{MEANING OF IT IN COLLEGE PHYSICAL EDUCATION TEACHING}

\section{A. Optimization of the Teaching Environment}

Typically, students are some of the more intuitive and objective image of infection and strong interest in things, and like the contact of these things in terms of acceptance of these things, they are manifestations easier. The IT multimedia software teaching just reached such a request, but it may be some learning staying power that is not strong, rational thinking is relatively weak for students to provide some help. Through multimedia software, applications in physical education can give full play to the dominant position of student learning, students' knowledge in the extended range, while also reducing the time teachers teaching, teaching quality and efficiency has a role in promoting further stimulate the students' creative thinking. Therefore, in the process of teaching college sports, the use of IT can optimize the teaching environment, but be also an important way to improve the promotion of teaching effectiveness.

\section{B. Information Construction of College Sports}

The main role of IT is to replace and extend the function of human cognitive information, and with the progress of science and technology, information technology has entered a stage of the development of modern information technology. Contemporary education information application of platform development environment is based on the construction of the campus network to facilitate information management and resource sharing on campus. Contemporary School sports have information construction, network construction is the foundation, and resource development is the core factor. In order to change the traditional management model, important information management of transfer process is mainly reflected in the effective control of electronics, information technology and quantitative implemented to improve efficiency and the development of sports information management automation. University information efficiently has become the consensus of teaching sports management department, college sports teaching information technology, for improving the situation of sports management schools and improving the overall quality of the teaching staff is of great significance. 
The use of modern information technology teaching has its methods that are innovative and diverse, to overcome the past teachers edge demonstrations, while explaining the traditional physical education teaching. The use of modern information technology is in line with curiosity of young people and the psychological characteristics of novelty, it can also create better situational and emotional experience, and cause and maintain students 'attention and interest, which can stimulate students' enthusiasm for learning, to mobilize students to learn enthusiasm. The use of modern information technology to assist teaching can greatly increase classroom capacity, increase the information density, improve teaching efficiency, and enrich students' learning content. The use of computers to store and recall functions can display a variety of information related to the content and the teaching of this lesson, the picture and sound in the classroom are to help students master the frontiers of knowledge more than the content of textbooks or the discipline.

The use of modern information technology can be interactive teaching. Today's school physical education is only in the classroom, teachers' impart knowledge is limited, how to improve the students' sports knowledge base needs to solve the problem. Teachers can use student curiosity and strong features, play some interactive Flash courseware in the classroom, teach students to interact sports, this can stimulate students' interest in learning to improve learning outcomes.

\section{THE USE OF MODERN INFORMATION TECHNOLOGY CAN BE A MODERN PHYSICAL EDUCATION MANAGEMENT}

The annual sports standards and the final exam scores should be carried out in terms of PE teachers of statistics. There are standards for student achievement sport, if you have the appropriate supporting computer software, teachers will only need to enter the sport of individual achievement, which corresponds to the score are considered. Full use of modern information technology is to implement school sports teaching management, which can greatly reduce the workload of physical education teachers.

Innovation is the main teaching of Physical Education Teachers, with it modern emphasis on people-oriented, student-centered, student physical and mental development, to develop their sporting interests and to improve their personality centered. Transfer of Physical Education Centre was not relaxed requirements for teachers, but it put forward higher requirements. From the information point of view, the main factors affecting sports Innovative Sports Teaching Physical Education teachers lack obtain information awareness and ability, namely the lack of PE teachers should sport IT. IT refers to people's awareness of the importance of information as well as information on the activities of people in a variety of demonstrated ability and overall quality, including information awareness, information, information thinking, means of information and information ethics respect for ethical and other specific content. From the viewpoint of Physical Education, Sport IT can be understood as PE teachers teaching information related to sports and its characteristics, the value of knowledge and ability to obtain analysis, application information and other aspects of Physical Education. Physical Education is including information awareness, physical education information capabilities, information concept of Physical Education and Sports Teaching information ethics and other aspects.

Information Awareness refers to people's information that needs of self-awareness, sensitivity of information that people are people and social phenomena of nature, behavior, opinions, etc. from the information theory point of view of understanding, feeling and evaluation. From the perspective of teachers, physical education teachers' awareness of information refers primarily to obtain psychological tendency Sports Physical Education and sensitivity of information. Physical Education that needs to innovate, innovation of a wealth of information has some value.

\section{CONNOTATION OF MODERN INFORMATION TECHNOLOGY AND PHYSICAL EDUCATION TEACHING}

IT is an enduring topic in-depth development of educational reform; IT becomes boost power evolving education. They make classroom that had a substantial effect change, development and IT teaching into a close relationship. Modern IT and teaching activities combined together, IT is not just as a tool to assist teaching, IT itself has a comprehensive, interoperability, resource sharing, etc., which can create a suitable learning environment that can continue to improve students' self learning ability, practical ability, in turn, it can cultivate innovative talents. Thus, the computer technology is used in teaching reform, which would be more effective to change the traditional teaching structure, cultivating innovative talents to adapt to the development of society. When the use of modern information technology is to physical education, in fact, it is a new type of sports teaching methods, specifically, it is to explain the PE teachers during sports programs, we can have different levels of knowledge, methods and information technology, human resource content interspersed in together. Thereby, it is allowing students to learn more sports knowledge. The modern IT and sports programs combine, mainly to achieve IT services for the purpose of Physical Education.

\section{IN IT FOR PHYSICAL EDUCATION TEACHING}

\section{A. The Impact on All Elements of Physical Education}

The purpose of education is changed. With the development of information technology, knowledge-based society of talent made new demands; the purpose of the school physical education also will be changed. Physical Education is no longer the emphasis on the technical how to teach, how to learn the operation, but "people-oriented" pays more attention to cultivating students' independent learning ability and creativity, responsibility and so on. (2) It changes the way students learn, the dominant position of highlights. Traditional sports teaching system is based on teacher explanations, demonstrations, student attendance, imitating the form of practice-based teaching, students' learning process is a passive acceptance of the process. In the multimedia network teaching, students are from accepting 
"indoctrination" passive position into active participation and the dominant position of inquiry. Students under the guidance of teachers can autonomously and communicate multimedia network teaching system, and according to their own situation, they choose the learning content, they determine the learning progress. Through interactive online teaching activities, such as real-time lectures, real-time Q \& A, symposia, etc., they combined with a wealth of information resources, which can greatly improve the ability of students to self-education, so that students learn more wealth initiative and creativity.

\section{B. Integration of PE Course Resources under IT}

Course curriculum resources are conditions for the formation and implementation of elements of the source program. Extensive use of IT resources has the impact of the concept of the traditional curriculum. Curriculum resources are no longer a single textbook, books and other printed products, including more network resources. This requires college physical education teachers to the times, to improve their acquisition; they should the ability to integrate curriculum resources. Teachers should participate in various forms of teacher training to improve the ability to access information and application level information on teaching. They should have ways of teaching resources IT like these: original teaching resources, network resources, and selfdeveloped teaching resources, and so on. In addition, the college PE teachers master these pathways to sports teaching as a precondition to enable the integration of various resources and sports programs. Meanwhile, the teacher lets the students as the main body and the owner of curriculum resources, creative development and use, to achieve the goal of independent learning and teaching cooperative learning.

There is a use of various channels of Physical Education of Teachers Training information that needs acquisition of awareness and information to promote innovation. We should enhance IT training for PE teachers, especially in the training of computer technology, network application capabilities, and broaden access to information Physical Education to improve its analysis, communication, application of sports teaching information skills. We should strengthen hardware construction; College Sports Research Department should be devoted to the establishment of a computer studio. According to the characteristics of Physical Education, they are specializing in teaching information acquisition, analysis, training, application ability. They hire an expert on sports information and introduce training sports applications to improve the ability of sports information. And they introduce knowledge acquisition, analysis and processing capabilities such as the use of sports application software, sports courseware, sports information aspects to encourage PE teachers in Physical Education and management Sports information technology, including multimedia courseware, VCR, projector use, the application of computer networks. They are to change the traditional information acquisition, analysis habits, to master modern information technology as soon as possible. For the ability to have some sport sports information workers, we should strengthen its sports information moral education. In physical education information software development, interpretation and communication process should adhere to scientific and health of unity, so that information can really Physical Education for Physical Education innovative services.

\section{Using the PE IT Allows Students to Establish a Clear Action Performance}

We should have clear action formed the basis of representation that is an important skill, which comes from the teaching process explanations, demonstrations, presentations and other teachers. PE Teaching with some technical movements is difficult to describe in words clearly, especially some of the technical details of the vacation after the great difficulty to explain the effect of the demonstration. It is not satisfactory. Multimedia will be able to very easily solve these difficult problems, to help students understand the operation, concept formation, to remember structures and establish a clear action in the brain representation. For example, in teaching high jump, high jump action there is a vacant process, and teachers can only be complete coherent demonstration of technical movements, we cannot stay in the air for students to look at the aerial action. Beginners, such demonstration in the brain leaving only a vague impression fragmented, are not conducive to their learning. The use of multimedia courseware can think fast and fast, think slowly and slowly, students are able to establish a clear action representation.

\section{CONCLUSIONS}

In college sports teaching, modern IT and Physical Education are to integrate and deepen the sports curriculum reform, to implement the spirit of the curriculum standards, the use of modern information technology is supporting the completion of the task of Physical Education Teaching Reform. It is a major trend in college sports; its role cannot be overlooked. Modern IT is conducive to promote the development of school physical education. The use of modern information technology can greatly improve the efficiency of Physical Education. Through modern teaching management software, you can greatly reduce the workload of physical education teachers. In physical education, teachers should be fully aware of the important role of network technology in the modern information technology, the use of network resources, sharing of resources.

\section{References}

[1] Wei Yan. Resolve the specific application of information technology in the College Physical Education [J] electronic test, 2013,22: 203-204.

[2] Zhang Xiaojing. IT: Booster Sports modern teaching reform [J] Gansu Education, 2010,22: 36-37.

[3] Peng Chong. Effective use of IT in junior Physical Education Teaching [J] youth sports, 2014,07: 82-83 + 85.

[4] Wu Gengye. Explore the modern IT and Physical Education Integration [J] Jilin Institute of Physical Education, 2005,01: 110-111.

[5] Deng Lisheng. IT integration and College Physical Education [J] Chinese Adult Education, 2011,03: 115-116.

[6] Hu Wenyi. Theatrical effect of the integration of IT and physical teaching and suggestions [J] Nanchang College of Education, 2011,05: 183-184.

[7] An Weiqiang. Value of modern information technology in Physical Education Research [J] Heihe Science Journal, 2010,10: 107-108. 